\title{
RESENHA \\ ALGUMAS PONTUAÇÕES FUNDAMENTOS DA EDUCAÇÃO: RECORTES E DISCUSSÕES
}

LIMA, P. G. (Org.). Fundamentos da educação: recortes e discussões. 1. ed. Jundiaí: Paco Editorial, 2014. v. 1.

Caracterizado como uma organização de obra, Fundamentos da Educação: recortes e discussões - Volume 1 reúne elementos ricos e instigantes no desdobramento dos eixos histórico-filosóficos da área, de maneira clara e objetiva. A obra é organizada por Paulo Gomes Lima, Doutor em Educação Escolar pela Universidade Estadual Paulista, Araraquara, SP, e Professor do Programa de Pós-Graduação em Educação da Universidade Federal de São Carlos, Campus Sorocaba, da Grande Dourados e do Departamento de Ciências Humanas e Educação (DCHE) da mesma Instituição.

O volume em tela, por seu percurso, não necessariamente, cronológico, mas com riqueza de detalhes temporais, propõe-se, entre outros, a contribuir como elemento de conscientização do pesquisador, do professor, dos estudantes e dos estudiosos da educação como uma possibilidade de atuação intencional em uma sociedade conflituosa, contribuindo para transformações sócio-históricas e políticas de reflexão-na-ação sobre a realidade vivida (p. 5).

Lançado pela Paco Editorial, o livro contém 240 páginas, organizadas em 13 capítulos; contém a respectiva bibliografia e informações sobre o organizador e todos os autores de cada capítulo e reflete recortes sobre o pensamento pedagógico de "alguns" representantes da história da educação concernente à época moderna em diante.

O itinerário de cada capítulo apresenta contribuições históricas que auxiliam na contextualização da educação contemporânea em um movimento condicionado pelo homem e por forças que podem ou não justificar as intencionalidades e

\footnotetext{
* Mestranda em Educação pela Universidade Federal de São Carlos Campus Sorocaba; Docente da Rede Oficial de Ensino do Estado de São Paulo; meira.chaves@gmail.com
} 
cunhagens ideológicas que lhes sustentam. Daí ser necessário o “olhar" para cada representante do pensamento pedagógico em destaque e conhecer um pouco de sua história pessoal, seu conceito de educação e maneiras de conduzi-la na escola, suas principais obras e em que medida seu pensamento se aproxima da validação dos saberes e fazeres da educação na atualidade (p. 7).

No capítulo I, O Pensamento pedagógico de René Descartes, Lima desdobra a dúvida metódica de Descartes; destaca que, no pensamento metódico do autor, o que não é certo e evidente é falso. Uma única razão para duvidar de determinado princípio, e ele será considerado falso em sua totalidade, pois não é próprio à luz natural confiar em quem já lhe enganou, mesmo uma única vez. Nessa diretiva, todos os conhecimentos sensíveis são considerados falsos, pois nos dão razões para deles duvidarmos; mesmo das coisas concretas é possível duvidar. A defesa cartesiana não é de uma inteligência construída, mas inata, diferente das proposições centradas no empirismo.

No capítulo II, escrito pela Professora Lilian Tatiane Candia de Oliveira, destaca-se a contribuição de Jean-Jacques Rousseau para a educação, seus pressupostos sobre a concepção de sociedade política e sua concepção e proposta educacional de educação.

No capítulo III, de Ribamar Nogueira da Silva, apresenta-se o pensamento pedagógico do filósofo Immanuel Kant. Nesse capítulo discute-se o caminho para o uso prático da razão em Kant, para, na sequência, tratar da educação moral, entre os conceitos de disciplina e liberdade, e, por fim, suas convicções e orientações pedagógicas.

No capítulo IV, Telma Elizabete de Moraes debate o pensamento pedagógico de Marx. O propósito nesse capítulo é conhecer as contribuições do pensamento pedagógico marxiano, em uma perspectiva de articulação com o trabalho: instrução intelectual, educação física e treinamento tecnológico. Evidencia a Professora Telma que, entre as contribuições sinalizadas por Marx, destaca-se a defesa do ensino universal, público, gratuito, obrigatório e laico para todos que inspiraram propostas revolucionárias na pedagogia contemporânea, como a Pedagogia Histórico-Crítica.

Kleyton Carlos Ferreira é autor do V Capítulo, no qual discorre sobre o pensamento pedagógico de Jean Piaget (1896-1980). Nele, tem-se como foco o entendimento de que a inteligência, para Piaget, não é produto da hereditariedade, mas uma possibilidade humana. Destacou quatro estágios no pensamento e comportamento infantil, os quais são caracterizados pelas denominações: sensório-motor, pré-operatório, operatório concreto e operatório formal.

No capítulo VI, de Cristiane de Sá Dan, contextualiza-se o pensamento pedagógico de John Dewey e faz-se conhecer as suas concepções educacionais em 
três eixos: os fundamentos do pensamento pedagógico de Dewey, a educação como reconstrução da experiência e a concepção de professor reflexivo de John Dewey.

No capítulo VII, O pensamento pedagógico de Vygotsky, de autoria da Prof. Dra. Izabella Mendes Sant'Ana e do Professor Caio Cesar Portella Santos, apresenta-se uma breve introdução acerca da vida e do pensamento de um relevante teórico da Psicologia e da Educação, fundador da Teoria Histórico-cultural: Lev Seminovitch Vygotsky e algumas das principais contribuições de sua teoria para a área educacional.

No capítulo VIII, escrito por Carolina Aparecida Rosa, discutem-se algumas conceituações acerca da proposta educativa de Antônio Gramsci, traduzida pela Escola Unitária. No texto, discute-se que na linha de raciocínio gramsciana destacam-se as relações de trabalho no processo de educação, e a luta de classes é vista pela sua dimensão político-educacional.

Angélica Bellodi Sant'Ana Furlan é a escritora do capítulo IX, O pensamento pedagógico de Pierre Bourdieu. Nesse trabalho, aborda-se o pensamento pedagógico de Bourdieu enquanto contribuição para uma Sociologia da Educação, que anuncia como a cultura, o poder e o ensino estão articulados para a reprodução e a manutenção da forma como a sociedade está organizada. Também se discute, em um primeiro momento, a trajetória de vida do autor e suas produções, bem como suas contribuições para a esfera educacional, abordando os principais termos cunhados por Bourdieu para explicitar sua teoria da reprodução cultural e da violência simbólica exercida pelas instituições escolares.

A partir do pensamento pedagógico de Anísio Teixeira, no capítulo X, escrito por Flávia Leila da Silva, discute-se sobre as concepções pedagógicas desse expoente da educação brasileira, um dos principais representantes do movimento escolanovista, com importante atuação no cenário educacional como intelectual e gestor de sistemas educacionais, e, finalmente, são consideradas as críticas que o pensamento de Anísio Teixeira recebeu e ponderou-se sobre os pontos e contrapontos presentes em sua concepção pedagógica e sobre as influências no cenário educacional contemporâneo.

No capítulo XI, da professora Ester Chichaveke, problematiza-se a Teoria da Complexidade sistematizada por Edgar Morin. A crítica ao paradigma da simplificação, caracterizado pela departamentalização e disjunção do conhecimento em disciplinas, e a proposta de superá-lo por meio do pensamento complexo balizarão as discussões, aqui, propostas. A reforma da consciência, exigência central da abordagem moriniana, suscita o desafio de desenvolver uma visão amplificada da realidade, considerando-a em seus variados desdobramentos, além de propor a transposição das 
verdades absolutas arrogadas pelo conhecimento clássico e supervalorizadas pelo racionalismo científico. No entanto, destaca a autora que as novas formas de pensar e agir postuladas pela abordagem complexa ainda não se fizeram suficientes para provocar a superação da desigualdade social e as contradições dela originadas.

Gabriel Ribeiro Demartini, no capítulo XII, delineia um percurso em relação a algumas dimensões do pensamento pedagógico de Paulo Freire, uma plataforma simples, mas que permite um primeiro passo para a compreensão de um autor de tamanha magnitude para o contexto educacional brasileiro e mundial. Para isso, inicia com uma introdução à sua biografia (Conhecendo um pouco de sua história), perpassando alguns pontos de sua concepção educacional assumidamente política, dialógica e humanizadora (A pedagogia de Paulo Freire), promovendo a crítica à "educação bancária" ( $A$ "educação bancária), atingindo a estruturação dos conteúdos programáticos, no momento em que se adentra no conceito de tema gerador como espinha dorsal da estruturação curricular ( $O$ conteúdo programático em Freire), quando, então, engloba a continuação do pensamento por outros autores a partir da obra freireana (Contribuições ao pensamento freireano a partir da literatura especializada) e, por fim, conclui que o pensamento pedagógico de Paulo Freire é atual, recorrente e pertinente diante da escola brasileira em meio à problemática da divisão social de classes.

No capítulo XIII, escrito pelo Prof. Dr. Fabrício do Nascimento, são apresentadas algumas informações sobre o educador e pesquisador Dermeval Saviani, bem como suas principais ideias a respeito do papel da educação escolar no contexto da sociedade capitalista. A corrente pedagógica a qual Saviani denomina Pedagogia Histórico-Crítica é uma proposta pedagógica transformadora, tendo por horizonte o desenvolvimento de uma práxis revolucionária, oposta às tendências pós-modernas que emergiram no âmbito da reestruturação produtiva do capital e do avanço da ideologia neoliberal, a qual desvaloriza a educação pública e o saber escolar sistematizado.

Por sua coerência interna, escolha de ênfases e atualidade, o livro Fundamentos da Educação: recortes e discussão, é indicado todos aqueles que desejarem aprofundamento em discussões epistemológicas concernentes à área educacional. A obra apresenta contribuições relevantes, e recomenda-se a sua leitura e utilização, inclusive em cursos de graduação, em nível de graduação, além de estudos de aprofundamento em nível stricto sensu. 